\title{
A RELAÇÃO COM O SABER, O DESEJO PELA DOCÊNCIA E O SENTIDO DA FORMAÇÃO DO PROFESSOR DE MATEMÁTICA DA REDE PÚBLICA ESTADUAL CEARENSE
}

\author{
Célio de Mendonça Clemente \\ Universidade Federal de Sergipe - UFS \\ prof.celiomendonca@gmail.com \\ Denize da Silva Souza \\ Universidade Federal de Sergipe - UFS \\ denize.souza@hotmail.com
}

\begin{abstract}
Resumo
Este artigo faz parte de uma pesquisa em fase de conclusão do mestrado acadêmico em Ensino de Ciências Naturais e Matemática pela Universidade Federal de Sergipe/UFS e propõe uma discussão sobre a relação com o saber do professor de Matemática de três escolas da rede estadual cearense a partir dos móbeis que os levaram à escolha pela docência nessa área, implicando no seu "desejo de ser professor" e do sentido da formação continuada, para esses sujeitos. O estudo baseia-se na perspectiva charlotiana (a relação com o saber) buscando, a partir dos relatos dos sujeitos, compreender a relevância que esses professores dão sobre a formação inicial e continuada como parte contributiva para a sua atuação docente no Ensino Médio e na área de Matemática. A coleta de dados foi realizada com aplicação de questionários aos professores e realização de três encontros de grupo focal. A relação com o saber desses professores se apresenta na sua dimensão epistêmica quando, após as discussões e debates dos grupos focais, eles demonstram mudar suas compreensões; e nas dimensões identitária e social, quando apresentam uma mobilização quanto à formação continuada fora da escola.
\end{abstract}

Palavras-chave: Relação com o saber; Formação inicial e continuada; Professor de Matemática.

\begin{abstract}
This article is part of a research in the final phase of the Master 's Degree in Teaching Natural Sciences and Mathematics by the Federal University of Sergipe/UFS and proposes a discussion about the relation with the knowledge of the Mathematics teacher of three schools of the state network of Ceará From the mobiles that led them to the choice of teaching in this area, implying in their "desire to be a teacher" and the sense of continued formation, for these subjects. The study is based on the charlotian perspective (the relation with the knowledge) seeking, from the reports of the subjects, to understand the relevance that these teachers give about the initial and continued formation as a contributive part to their teaching performance in High School and in the area of Mathematics. The data collection was carried out with the application of questionnaires to the teachers and three focal group meetings. The relation with the knowledge of these teachers presents in their epistemic dimension when, after the discussions and debates of the focus groups, they demonstrate to change their understandings; And in the identitary and social dimensions, when they present a mobilization regarding the continued formation outside the school.
\end{abstract}

Keywords: Relation with the knowledge; Initial and continued formation; Mathematics Teachers. 


\section{INTRODUÇÃO}

A formação inicial é requisito para a prática docente em qualquer área do conhecimento, pois o professor precisa saber aquilo que vai ensinar e como ensinar. Por isso, nessa formação são desenvolvidos os saberes disciplinares, os da profissão e os curriculares. Esses últimos, também são construídos nas escolas com a construção do projeto pedagógico da escola. A escola é também o ambiente propício ao desenvolvimento dos saberes experienciais por parte do professor.

Dessa forma, assim, como a formação inicial é relevante para o ingresso na docência, a formação continuada é útil para que o professor trabalhe com qualidade, uma vez que pode complementar à primeira, atualizando-o quanto às metodologias de ensino, as diretrizes e parâmetros educativos etc. Ambas são intrínsecas à relação do professor à sua atividade docente, ao desejo de ser professor e ao sentido que dão à própria formação, se constituindo, portanto, como campo de conhecimento para o desenvolvimento da relação com o saber.

Em particular, para os professores de Matemática pesquisados, o ingresso na profissão está vinculado a alguns móbeis que se consolidaram ao longo da sua formação inicial, alimentando assim, o seu desejo de ser professor nessa área do conhecimento. Ao mesmo tempo, a formação continuada confirma esse desejo pelo sentido de ser professor e da necessidade de continuar formando-se tanto no âmbito da escola quanto fora dela.

O presente trabalho faz parte de um projeto de pesquisa em fase de conclusão (vinculado ao mestrado em Ensino de Ciências Naturais e Matemática da Universidade Federal de Sergipe-UFS, cujo objeto de investigação foram as práticas educativas do professor de Matemática com ênfase à "nova concepção"1 do ENEM) e tem como objetivo apresentar os resultados quanto à formação inicial e continuada do professor de Matemática do Ensino Médio das escolas pesquisadas, sob a perspectiva da relação com saber, nas seguintes dimensões dessa relação: epistêmica, identitária e social.

Para tanto, este texto compõe-se de três partes. A primeira diz respeito à fundamentação teórica com base na relação com o saber; a segunda descreve

\footnotetext{
${ }^{1}$ Embora, o objeto da pesquisa tenha buscado retratar uma nova fase do ENEM, à época do projeto, atualmente (antes mesmo desta pesquisa ser concluída), o Ministério da Educação já está anunciando novas políticas educacionais acerca do Ensino Médio e, por conseguinte, do ENEM. A presente pesquisa tem ênfase nas práticas educativas vigentes até ano letivo 2016.
} 
metodologicamente como ocorreu a pesquisa e a terceira consiste na análise dos resultados e discussões.

\section{A RELAÇÃO COM O SABER, ENQUANTO PERSPECTIVA TEÓRICA}

A atividade docente tem a peculiaridade de aglutinar situações de ensino, formação e aprendizagem. Para o professor, a formação inicial é importante para obter conhecimento teórico-prático nas competências para ensinar. A formação continuada tem igual relevância porque na tarefa de ensinar, o professor também aprende (FREIRE, 1996). Ou seja, de um lado, o ato de ensinar é intencional e sistemático e exige saberes próprios. As instituições formadoras de professor, por meio da formação inicial, cuidam de prepará-lo nos saberes da formação profissional, disciplinares e curriculares (TARDIF, 2013). De outro lado, os saberes experienciais são desenvolvidos no quotidiano do professor, ao exercer o ofício de ensinar.

Tais saberes exigem do professor a sua construção e reconstrução por meio da ressignificação dos conhecimentos da disciplina que ensina e daqueles que adquire ao longo da vida. A escola, por sua vez, é ambiente fértil para essa ressignificação (fruto da sua relação com o saber). Os saberes da docência estão, portanto, ligados à prática educativa do professor e fazem parte da sua identidade profissional.

Uma identidade profissional se constrói, pois, a partir da significação social da profissão; da revisão constante dos significados sociais da profissão; da revisão das tradições. Mas, também da reafirmação de práticas consagradas culturalmente e que permanecem significativas (PIMENTA, 2008, p. 19).

A articulação das decisões do professor em sala de aula com a sua própria relação com o saber resulta das interações que tem consigo mesmo, com o outro (principalmente, com os alunos) e com o mundo (CHARLOT, 2000). Quando usa a relação com o saber em sala, o faz por meio do seu discurso pedagógico ${ }^{2}$ que, por sua vez, não restringe-se à disciplina e à escola, mas serve para provocar os processos de ensino e aprendizagem.

A relação com o saber é, para Charlot (2000, p. 80-81), “a relação com o mundo, com o outro, e com ele mesmo, de um sujeito confrontado com a necessidade de aprender; [...] é o conjunto (organizado) das relações que um sujeito mantém com tudo que estiver relacionado

\footnotetext{
${ }^{2} \mathrm{O}$ discurso pedagógico é um meio de produzir conhecimentos, dar vozes e valorizar as especificidades da linguagem na tônica do ensino, promovendo assim, a construção do saber, do desenvolvimento moral e intelectual, considerando as infinitas possibilidades discursivas [...] (FREITAS; SAMPAIO, 2010, p. 01).
} 
com "o aprender" e o saber". Envolve tudo aquilo que o sujeito se utiliza para aprender. Ele a constrói, ao mesmo tempo em que a vivencia na busca pelo saber e pelo aprender. Esse saber é amplo, pois ocorre engajado a qualquer atividade, em diferentes dimensões: epistêmica, identitária e social (Antunes, 2007).

A dimensão epistêmica relaciona-se ao saber como experiência do sujeito no que concerne ao aspecto intelectual da sua relação com o aprender. Para Ribeiro (2012, p. 24), essa dimensão da relação com o saber divide-se em: "relação com um saber-objeto, relação com uma atividade executada pelo corpo e a relação com um dispositivo relacional". Para Charlot (2000) a dimensão epistêmica do saber-objeto ocorre na medida em que o sujeito se apropria de um saber (representado num objeto) que não possui e passa do estágio de não posse ao de posse. Mas, para isso, pode ser na condição de uma linguagem, de uma atividade ou da própria relação social que o sujeito tem com o meio em que vive.

Por exemplo, quando um sujeito passa a se apropriar de um conhecimento matemático, a partir da linguagem específica da Matemática (signos, símbolos, sinais, gráficos etc.), ele passa a compreender e identificar as diferentes representações, conforme o dado conhecimento permita (linguagem numérica, algébrica e/ou geométrica). Nessa situação, ele precisa estar em atividades que lhe possibilitem a compreensão de tal conhecimento. Ler um texto no livro, resolver problemas com aplicações de conceitos matemáticos, fazer experimentos. As atividades da relação saber-objeto não implicam necessariamente em atividades corporais, segundo Antunes (2007), elas vão mais além, depende qual relação que o sujeito tem com o saber (em questão).

Há ainda, a dimensão epistêmica como um dispositivo relacional definido por sentimentos e emoções em situações e em atos. Ou seja, associa-se ao domínio das formas intersubjetivas em uma relação entre os sujeitos (relação com o outro) e consigo mesmo. Quando o sujeito passa a comportar-se em função de princípios que aprendeu configura-se um exemplo da dimensão epistêmica relacional. Então, apropriar-se da arte de ensinar Matemática, são características da dimensão epistêmica, sob as três condições - apropriação do conhecimento matemático a ensinar; apropriação da própria atividade de ensinar (conhecimentos pedagógicos como a didática entre diferentes metodologias e recursos didáticos) e apropriação das intersubjetividades nas relações com o outro (professor e alunos, entre seus pares e toda comunidade escolar). 
A dimensão identitária denota que a aprendizagem ocorre a partir de um sentido na e para a vida do aprendiz. Para Ribeiro (2012, p. 26), “a aprendizagem só se realiza quando existe um sentido, quando faz sentido por referência à vida do sujeito, suas relações com os outros, suas experiências, suas expectativas, a imagem que tem de si e aquela que quer transmitir de si aos outros". Ou seja, o sujeito deve ser compreendido como ocupante de uma posição social, com histórias de conquistas e rupturas, de anseios e desilusões, do vir a ser ou tornar-se alguém ou de profissionalizar-se. Por outro lado, pelas vias da aprendizagem, tem o domínio do saber pela dedicação ou da sua vontade de buscar o saber (CHARLOT, 2000).

A dimensão social se interconecta às demais abordagens e se articula às relações que o sujeito tem com o outro. Começa nas relações familiares e ampliam-se na sociedade, com os ciclos de amizades e demais relações sociais, tornando-se reais quando o sujeito as utiliza para aprender. Por exemplo, nessas relações, quando a cultura, costumes, funções profissionais, etc., possibilitam a construção, pelo sujeito, da sua história profissional e sua própria história na família e na sociedade, configura-se aí a dimensão social da relação com o saber (ANTUNES, 2007).

A relação com o saber faz parte da atividade docente e das práticas educativas do professor, sendo "matéria-prima" para desenvolver o seu trabalho. Almeida (2012, p. 111) reafirma que "o saber é o centro da experiência escolar". A centralidade do saber na escola e nas suas atividades educativas se vincula à existência de uma função social.

Dessa forma, o professor precisa construir, fortalecer e diversificar a sua relação com o saber (nas dimensões epistêmica, identitária e social) por meio da formação docente no âmbito da escola e fora dela. Quando isso ocorre, para Soato $(1999$, p. 01) “[ [...] tem-se o saber como objeto de desejo". Isso permite ao professor aprender a utilizar metodologias e atividades diversificadas e amplia o leque de possibilidades para a sua prática.

Nessa prática, o professor aprende pelo domínio das situações contextualizadas e do seu planejamento, acionando duas formas de mediação: a prática do saber e o saber da prática. O seu entendimento consiste em articular as tensões entre as lógicas dos saberes e das práticas nesses níveis mediadores (CHARLOT, 2005). Desde a formação inicial que o professor de Matemática confronta-se com essas tensões porque tem de se preparar nos saberes próprios da docência (TARDIF, 2013).

$\mathrm{Na}$ Matemática, os saberes dos conhecimentos pedagógicos e dos conteúdos integram as discussões sobre a formação do professor. Nesse caso, o licenciando convive com a 
ambiguidade de desenvolver seus saberes a partir de um discurso pedagógico que não responde totalmente às necessidades de formação. Isso pode vincular-se ao fato de que, nessas licenciaturas, o conhecimento matemático acadêmico (não didatizado) sobrepõe-se ao escolar (MOREIRA; DAVID, 2010).

Essa lógica não corresponde à realidade exigida pela civilização cognitiva contemporânea que fundamenta-se na evolução do saber e do saber-fazer, próprios do desenvolvimento de competências e habilidades (CAMPOS, 2013). Dessa forma, é preciso que instituições de ensino superior tenham de redirecionar os currículos das licenciaturas em Matemática para formar professores sob a perspectiva da Matemática Escolar.

\section{METODOLOGIA}

Esta pesquisa é descritiva quanto ao objetivo porque privilegia descrições de experiências por meio de respostas abertas em questionário e em grupo focal; qualitativa com abordagem fenomenológica. Suas características, abordagem, técnicas e instrumentais correlacionam-se à proposta de investigação e corroboram para coletar os dados necessários para responder à necessidade de compreensão da relação com o saber, o desejo de ser professor e o sentido da formação para os sujeitos da pesquisa.

Tais sujeitos são dezessete professores de Matemática de três escolas da Região Metropolitana do Cariri (RMC) no Estado do Ceará. Sendo desses profissionais, somente treze participaram efetivamente da pesquisa e para preservar as suas identidades foram codificados da seguinte forma: PA1, PA2, PA3, PA4, PB1, PB2, PB3, PB4, PB5, PC1, PC2, PC3 e PC4. A letra P significa professor, as letras A, B e C identificam cada escola pesquisada (também preservando a identidade) e o número, o professor da respectiva escola. Assim foram quatro professores da escola A e da escola C, cinco da escola B.

Os instrumentais e técnicas de pesquisa foram o questionário e os encontros de grupos focais. A escolha do questionário se deu por conta da necessidade de obter dados pessoais e profissionais a respeito dos sujeitos da pesquisa, bem como em relação à sua formação inicial e continuada com ênfase na sua relação com o saber e com a profissão. Os encontros de grupos focais foram em número de três e ocorreram de julho a setembro de 2016. Para cada encontro, houve o planejamento de um roteiro com base na formação inicial e continuada. 
Para Gatti (2005, p. 07), "no âmbito das abordagens qualitativas em pesquisa social, a técnica do grupo focal vem sendo cada vez mais utilizada". Nesse caso, foi útil para esclarecer algumas questões do quotidiano dos sujeitos (não evidenciadas nas respostas aos questionários) que dizem respeito à formação continuada e para mostrar aspectos da formação inicial, desvelando também, a sua relação com o saber pelo modo como interagem e retratam sobre sua atuação docente.

Os encontros foram realizados em uma das escolas e, no primeiro, as discussões focaram a formação inicial dos sujeitos e suas contribuições para a sua atuação no Ensino Médio e sobre os móbeis para a escolha da docência em Matemática; no segundo, o debate ampliou-se para o entendimento da formação continuada, suas necessidades no âmbito escolar e como algumas delas foram importantes para a atuação em sala; e no terceiro, as discussões foram relacionadas aos tipos de pós-graduação que possuem, sua realidade e o entendimento dos sujeitos sobre eles.

\section{ANÁLISE DE RESULTADOS E DISCUSSÕES}

Ao falar sobre a formação inicial e os móbeis para escolher essa área de formação, os sujeitos da pesquisa demonstraram “o desejo de ser professor de Matemática”. São motivos associados à trajetória de vida de cada um que fomentaram esse desejo, por exemplo, "afinidade com a educação e/ou herança, na família, mãe e irmãos trabalham com educação" (PA3). Nesse caso, a relação familiar pode fomentar o desejo de tornar-se docente tanto pelo ponto de vista identitário, como também, no âmbito social.

De forma complementar, há também o ponto de vista epistêmico, não podendo esquecer que na formação inicial são adquiridos os conhecimentos específicos para atuar como professor de Matemática, além dos pedagógicos e curriculares. No entanto, também, a partir da formação continuada, principalmente quando ocorre na escola, o professor se apropria do discurso pedagógico oficial e constitui o seu discurso próprio. Pelas ações que acontecem na escola, por meio das discussões na construção ou (re)elaboração do projeto pedagógico, nas reuniões ou formação de curta duração, esse discurso vai sendo instituído ao discurso do professor, tornando-se em conhecimento também.

Por outro lado, fora da escola, a formação continuada em nível de pós-graduação, torna-se um complemento dessa dimensão epistêmica, quando o professor busca fazer cursos 
de lato sensu ou stricto sensu. Nesse sentido, a formação inicial e continuada confirmam o "desejo de ser professor" e apontam para o "sentido dos sujeitos em buscar essa formação".

\section{O desejo de ser professor de matemática}

A formação inicial do professor é um indicativo do seu desejo de ser professor de Matemática. Assim, a formação apontada pelos sujeitos demonstra esse desejo, pois 88,24\% deles têm habilitação em Matemática, enquanto que os demais têm licenciatura em Ciências (curta duração) e Ciências Biológicas (áreas afins). Para atuar na docência, o professor precisa saber o que e como ensinar. Assim, pela formação inicial (formação na área, ou afim), percebe-se nos sujeitos pesquisados a aspiração e o “querer” ser professor de Matemática.

Sobre a relevância da formação inicial para o sucesso da sua atuação no Ensino Médio, os sujeitos evidenciaram que a formação na área de atuação contribui para uma prática educativa com qualidade, logo, é essencial, significativa e norteadora ao trabalho docente. Dentre os sujeitos, $62 \%$ enfatizaram-na como importante para a formação teórico/prática, reafirmando assim, o desejo de ser professor de Matemática nos seguintes relatos:

PA2 - "Importante, afinal é condição para um bom desempenho profissional";

PA3 - "É importante para o conhecimento específico (matemática), mas também a formação da metodologia e didática";

PB1 - "Muito importante, pois foi na graduação que tive a oportunidade, nos estágios, de conhecer a prática de sala de aula";

PC4 - "A formação inicial é a base para começarmos a edificar uma formação sólida, mas, é extremamente importante que teoria e prática sempre lado a lado".

Essa ênfase dada à licenciatura aponta que precisam contemplar os aspectos teóricos e práticos da formação. A sua qualidade, por outro lado, pode contribuir para despertar o significado que o licenciando dá a essa formação; implicando ainda, na sua relação com o saber e na construção da sua identidade profissional, podendo ingressar, ou não, na carreira docente. Para retratá-la, chamam à atenção as seguintes respostas:

PB5 - "Foi de fundamental relevância, pois nesse contexto surgiu o desejo de lecionar a disciplina";

PC2 - "[...] busquei exemplos na minha formação que me inspiraram a ser a profissional que sou hoje. Os melhores métodos, organização, postura, domínio de conteúdos, estratégias de aprendizagem e relação com os alunos são em parte, reflexo de todos que me ensinaram". 
Esses relatos mostram que nem sempre o ingresso na licenciatura em Matemática ocorre pela decisão de ser professor. Essa formação pode ter outros significados, contudo, pode ser nela, que o sujeito encontre o sentido e passe a ter o desejo de ser professor de Matemática. Nas suas respostas, os móbeis apresentados pelos sujeitos mostram com clareza, os fatores que determinaram as suas opções por se tornarem professores de Matemática.

$\mathrm{Na}$ análise dos dados, ao falar na relação do sujeito com a disciplina, se diz respeito à afinidade que se tem com ela. Pode ter sido estabelecida a partir das habilidades adquiridas ao longo da sua vida escolar; na construção da identidade do sujeito na sua relação consigo mesmo, com o outro e com o mundo; ou ainda, pode ser entendida como resultado do sucesso escolar, a partir do êxito na aprendizagem de conteúdos/saberes da disciplina de Matemática.

Alguns sujeitos tornaram-se professores de Matemática, a partir da relação com a disciplina e/ou respondendo a um chamado da profissão, incluindo aí, a convivência com outras pessoas que já atuavam na área. Isso se explicita nos seguintes relatos:

PA2 - "Vocação, pois tive oportunidade de exercer outras funções e em outras áreas";

PA3 - "Afinidade com a educação e/ou herança. Na família, mãe e irmãos trabalham com educação";

PA4 - "Professora por vocação. Matemática, por afinidade com a disciplina";

PC2 - "Afinidade com a disciplina, o gosto pelo desafio ou Resolução de Problemas e a habilidade em transmitir o conhecimento para outros, quando ainda era aluna no Ensino Médio";

PB5 - "A satisfação, a afinidade e reconhecimento dos discentes". (negritos meus).

Por outro lado, escolher e ingressar em uma profissão, também implica conhecer mercado de trabalho. As respostas dos sujeitos articulam-se "ao espaço no mercado de trabalho" e à "possibilidade de crescimento profissional". Esses móbeis demonstram que escolheram a área de Matemática visando se posicionar em uma atividade que necessitava de profissionais, mas que, talvez por essa carência, também, possibilita sucesso na atividade.

A opção por uma carreira profissional está ligada às vivências e decisões pessoais. Alguns sujeitos optaram pela docência em Matemática, orientados por desejos pessoais. Por exemplo, "satisfação pessoal e reconhecimento" (PB5); nesse caso, o sujeito vislumbra se posicionar como sujeito social a partir da sua profissão. Essa perspectiva se materializa nas respostas ligadas à "possibilidade de crescimento profissional”, explícita nos relatos a seguir: 
PB1 - "O fato de gostar da disciplina de Matemática; e a demanda de profissionais que era muito";

PB3 - "Gosto pela Matemática e amplo mercado de trabalho";

PB4 - "Sempre gostei de Matemática; e tinha bastante vaga para professor de Matemática no mercado";

PC3 - "O espaço no mercado de trabalho e a afinidade com a área de atuação";

PC4 - "Primeiro por identificar-me, segundo por crescer profissionalmente, e terceiro, para contribuir com o ensino e a aprendizagem do próximo". (negritos meus).

Os relatos desses sujeitos encaminham para o entendimento de que, para eles, na área de Matemática, parece certo, ante o ingresso, o crescimento na carreira docente. As motivações pessoais e profissionais desses sujeitos são imbricadas e, em sentido duplo, são interdependentes. Essas imbricações parecem ser o cerne dos seus desejos de continuar buscando a formação, tanto no âmbito da escola, quanto em cursos de pós-graduação.

\section{O sentido de buscar a formação continuada dos sujeitos}

A formação continuada, tanto em nível de pós-graduação (especialização, mestrado e doutorado) quanto nos cursos de curta duração e aperfeiçoamento, é relevante para a ação docente. As reuniões para estudos de diretrizes educacionais e análises de indicadores de resultados, bem como para a elaboração de planos de ação, também fazem parte desse tipo de formação. A formação no âmbito da escola faz parte do quotidiano dos sujeitos e são ligadas às suas atividades docentes. Os cursos promovidos pela escola ou sistema de ensino são úteis para a atualização das práticas educativas, por exemplo. Todos os sujeitos responderam que participaram de cursos de formação sobre o Ensino Médio nos últimos seis anos.

Essa referência cronológica é destacada pelo fato de que em 2009 houve reformulações no $\mathrm{ENEM}^{3}$ e, para tanto, o professor precisou fazer formação voltada para esse aspecto. Para os sujeitos da pesquisa, esses cursos são para o Ensino Médio, mas também voltados para cada área do conhecimento, incluindo a Matemática. São ofertados, por exemplo, cursos ligados ao Projeto Jovem do Futuro (PJF), Programa de Aperfeiçoamento para Professores de Matemática do Ensino Médio (PAPMEM) e Pacto para o Fortalecimento do Ensino Médio (PACTO). Tais cursos são contributivos para melhorar a prática educativa do professor. Essa perspectiva de melhoria é observada nos seguintes relatos:

\footnotetext{
${ }^{3}$ Exame Nacional do Ensino Médio, criado pela Portaria do Ministério da Educação (MEC) No 438, de 28 de maio de 1998.
} 
PA1 - "Contribuiu no reger da linguagem matemática apresentada ao aluno (livre de vícios da linguagem convencional)";

PA2 - "Refleti sobre minha prática de ensino";

PA3 - "Curso fornecido pela escola; sempre tiramos algo, por menos que seja, para melhorar";

PA4 - "Auxilia no planejamento das aulas";

PB1 - "O curso me alertou para conhecer melhor os alunos";

PB2 - "Contribuiu em aperfeiçoar técnicas de aprendizagem e rever nossa prática em sala de aula";

PB3/PB5 - "Fortaleceram minha fundamentação teórica, didático e pedagogicamente";

PC1 - "desenvolver maior interação com o programa e planos";

PC2 - "Contribuiu no sentido de abordar temas em sala de aula sob outra perspectiva";

PC3/PB4 - "O PACTO contribuiu para atualizar conteúdos e discutir a respeito de práticas de ensino. Melhorou minha prática pedagógica"; PC4 - "Para desenvolver melhor minhas habilidades e tornar-me um profissional competente em matemática".

Essas respostas destacam a relevância da formação continuada para a prática do professor. Na resposta do sujeito PC1, nota-se que o curso do qual participou, foi voltado para a interação do professor com os programas e planos de ensino. A formação continuada com essa ênfase revela-se tão necessária quanto os cursos focados nos conteúdos, métodos e práticas de ensino. Entende-se ser necessário que o professor conheça quais programas e planos são propostos e implementados no sistema de ensino e na escola.

Sobre como a formação continuada contribuiu para a atuação do professor no Ensino Médio, os sujeitos evidenciaram que, esse tipo de formação lhes possibilita aperfeiçoamento e mudança na prática educativa. Por exemplo, quando o professor responde: "o curso me alertou para conhecer e conhecer melhor os alunos" (PB1) e "me forneceu fundamentação teórica (didática, pedagógica e psicológica) para lidar com rotina de sala de aula" (PB3), são respostas que apontam para a relação com o saber do professor, em sua dimensão epistêmica, pois envolve as relações de apropriação do saber-objeto; do saber-fazer (a própria atividade docente na rotina da sala de aula) e da subjetividade e intersubjetividade enquanto sujeito social (relação com os alunos e seus pares).

Isso se reafirma ao relatarem: "aprofunda o conhecimento no Ensino Médio" (PA4) e "contribuiu no sentido de abordar temas em sala de aula sob outra perspectiva" (PC2). Por outro lado, a ênfase na reflexão sobre a prática pedagógica revela-se em respostas como: "melhorar rendimento e assunto específico junto à aprendizagem" (PA3); "metodologias, 
práticas inovadoras, reflexão sobre a função social da disciplina e a transdisciplinaridade" (PB5) e "esses cursos me dão uma base mais sólida para a minha prática" (PC3).

Quanto aos cursos de pós-graduação, embora, todos os sujeitos que responderam a essa questão tenham especialização, somente seis deles ressaltaram sobre as contribuições desses cursos para a atuação, como professor de Matemática. Suas respostas apontam para a melhoria dos saberes disciplinares (PB4 e PC2); para o fortalecimento dos conhecimentos profissionais (PB1, PB3, PC1 e PC2) e um deles (PC4) respondeu que contribuiu para "saber dimensionar um trabalho de pesquisa, especificamente dentro da prática de ensino". Dessa forma, entende-se que todas essas respostas dizem respeito ao que se espera em um curso de Especialização e estão ligadas à necessidade de qualificação constante dos professores.

Esses cursos de pós-graduação possibilitam qualificação ao professor no sentido de atender às demandas contemporâneas da atividade educativa. Uma característica, em particular, é que a participação do professor nesses cursos vincula-se à sua decisão, mesmo que, em alguns casos, seja motivada por fatores externos. Alguns professores podem enxergar a ascensão funcional como uma motivação. Outros móbeis podem ser a busca pelo conhecimento, a partir de uma visão prática, aprofundando a sua relação com o saber e a reflexão sobre o saber-fazer. Na perspectiva pedagógica, as práticas, métodos e inovações do ensino fazem parte dos estudos de pós-graduação. Sobre esses estudos apresenta-se o gráfico.

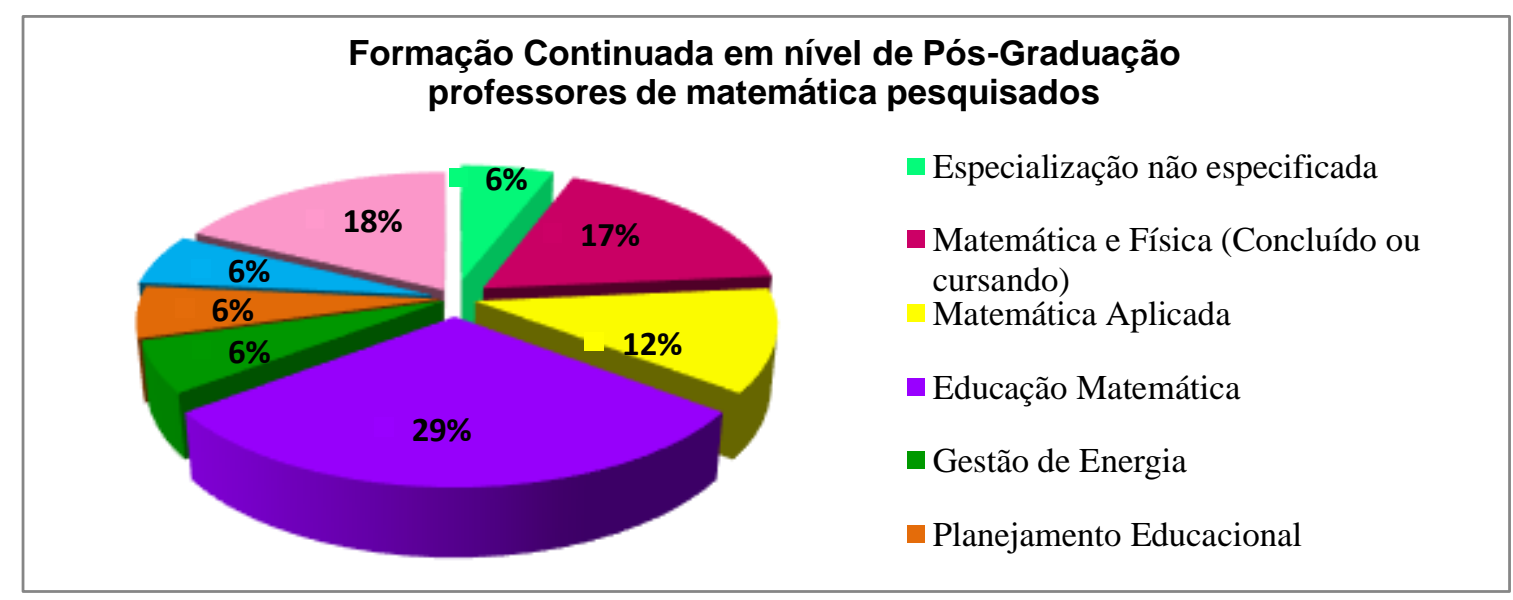

Fonte: Questionário de pesquisa (Ano: 2016)

Os dados do gráfico também revelam que esses sujeitos estão buscando a formação continuada em pós-graduação, no sentido de aperfeiçoar-se profissionalmente, embora um deles ainda esteja apenas em nível de graduação, um tem especialização fora da área de educação e um deles não declarou a área da sua especialização. 
Um dado relevante confirma que, para 70,59\% desses sujeitos, essa tendência ao curso de pós-graduação (concluído ou cursando) é na área de Matemática, sendo metade desses em Educação Matemática. Na outra metade, encontram-se aqueles que têm especialização em Matemática e Física, Matemática Aplicada e que tem mestrado no PROFMAT (um concluído e dois cursando), sendo 17,65\% com especialização e igual percentual com mestrado.

Os cursos de pós-graduação na área de atuação são indícios no desejo dos professores pesquisados continuarem no exercício da docência. Todos os participantes do grupo focal informaram sobre o desejo de ingressarem em um curso de Mestrado na área de Matemática ou em Educação. Afirmaram também, exceto um deles, que já participaram das edições do Exame Nacional de Acesso (ENA) ao PROFMAT. Isso, portanto, reafirma o desejo de ser e continuar sendo professor de Matemática.

Ainda em relação à formação continuada, chamam a atenção, os dados relacionados a aproximadamente $30 \%$ dos sujeitos pesquisados que têm especialização em Educação Matemática. Tais sujeitos estão buscando a formação na perspectiva contemporânea do ensino de Matemática. Esse campo do conhecimento tem como premissa, práticas educativas que valorizam a aprendizagem na perspectiva da contextualização, transdisciplinaridade e interdisciplinaridade. O ensino de Matemática sob esse foco faz parte do discurso pedagógico dos PCNEM, DCNEM e diretrizes para o ENEM com suas reformulações desde 2009.

Para perceber como a formação continuada é refletida nas práticas educativas do professor de Matemática, se questionou como a Educação Matemática se traduz no seu trabalho no Ensino Médio, no desejo de saber qual entendimento dos sujeitos. Suas respostas focaram as práticas educativas e a aprendizagem do aluno.

Ao falar da associação da Matemática ao dia a dia, da interdisciplinaridade e contextualização, da aproximação do conhecimento científico e a prática em sala de aula, da melhoria da comunicação com o aluno, da melhoria da prática de ensino e do despertar o educando para o ingresso na universidade, de certa forma, o professor está articulando a Educação Matemática à sua prática. Os relatos demonstram o entendimento dos sujeitos.

PA3 - "Tentando relacionar o assunto estudado na sala com está presente na vivência do dia a dia";

PA4 - "Educação Matemática se materializa através da aplicação de atividades e práticas fundamentadas na modelagem matemática, história da matemática, resolução de problemas, etc.";

PB1 - "Quando tentamos associar a matemática ao dia a dia, percebendo para que ela serve"; 
PB4 - "Na interdisciplinaridade com as outras áreas, nas questões contextualizadas voltada para a vida prática dos alunos";

PC1 - "Melhorando minha prática - na utilização de meios e tecnologias que facilitam o processo de ensino - aprendizagem";

PC3 - "Entendo que a Educação Matemática possibilita uma aproximação entre o conhecimento científico e a prática em sala de aula".

Percebe-se, ante esses relatos, a Educação Matemática "no quotidiano do processo de ensino-aprendizagem e nas atividades que interligam os estudos de fenômenos naturais e científicos ao aprendizado dos conceitos matemáticos" (PB3), bem como, "através dos resultados satisfatórios" (PC4) que o professor de Matemática tem como foco do seu trabalho, o aluno como sujeito da aprendizagem, vinculando tais elementos às suas práticas educativas.

De forma tímida, ou mesmo confusa, há comentários sobre as metodologias da Educação Matemática. Elas, por exemplo, a Resolução de Problemas, a Etnomatemática, Modelagem Matemática, etc., abordam o ensino tendo como foco, o aluno e sua aprendizagem. Assim, ao reconstruir o cenário da sua prática educativa, rever sua práxis e reavaliar o processo educativo, o professor pode fazê-lo por meio da Educação Matemática como parte do paradigma atual da educação.

Dessa forma, o sentido de buscar a formação continuada está ligado a sua qualificação profissional. Primeiro porque é necessário participar das reuniões, planejamentos e cursos da rotina docente. Em um segundo plano, o sentido de buscar a formação continuada presente no quotidiano desses profissionais, visto que são pós-graduados em nível de lato sensu, sendo um deles (sujeito PA1) tem mestrado concluído, enquanto que outros dois (sujeitos PA4 e PB4) estão concluindo.

Isso caracteriza a dimensão identitária da relação com o saber dos sujeitos porque constitui parte da sua identidade profissional. Ou seja, ao buscarem a formação continuada, na perspectiva de aprimorar os seus saberes e de refletir sobre as suas práticas de ensino, entende-se que estão se constituindo como sujeitos da sua atividade docente que ocupam um espaço preocupado em se qualificar para contribuir com a melhoria da qualidade da educação.

\section{CONSIDERAÇÕES}


As respostas dos professores contribuíram para compreender como a formação inicial (graduação) e continuada (planejamentos, cursos de curta duração e de aperfeiçoamento, especialização, mestrado e doutorado) se apresentam como determinante para trabalhar a contextualização do ensino de Matemática e como contribuem para formar o professor na concepção de Educação Matemática.

Para atuar na docência, o professor precisa ter domínio da sua atividade e, ao fazer isso, estará investindo na aprendizagem da sua profissão, ao mesmo tempo, em que constrói a própria identidade profissional. A forma como o professor aprende (o seu ofício), determina a sua compreensão da disciplina e norteia as suas práticas educativas. A formação inicial, portanto, é responsável por dar competência ao sujeito para atuar na atividade docente, sendo essencial à construção e domínio dos saberes docentes.

A formação inicial dos professores na disciplina que lecionam representa o seu desejo de ser professor e aponta que alguns móbeis contribuíram para a opção por ingressar na docência nessa disciplina. No caso desta pesquisa, os profissionais têm uma relação com a disciplina e associam a ela a possibilidade de sucesso no mercado de trabalho.

Os sujeitos pesquisados consideram que a formação continuada proposta pela escola é relevante porque lhes possibilita participar na construção do seu projeto pedagógico, no estudo das diretrizes educacionais, na análise de indicadores de resultados e planejar as práticas educativas e a rotina da sala. Portanto, demonstram interesse e sentem a necessidades de participar delas.

A formação em nível de especialização e o interesse em participar em um curso de Mestrado denota que os professores veem um sentido nesses tipos de formação. Isso é um indicativo de que os sujeitos encaram a formação continuada como um processo que se constrói de forma continua e constante, tanto no ambiente escolar quanto fora dele. Também representa a relação do sujeito com a profissão porque depende de decisão pessoal; explicita ainda, o sentido desse tipo de formação para esses sujeitos e aprofunda seus saberes docentes.

As discussões e questionamentos realizados na pesquisa, por meio dos grupos focais contribuíram para que os professores passassem a perceber que o trabalho coletivo e as discussões dos planejamentos, por exemplo, na análise de resultados de aprendizagem, também caracterizam-se como formação continuada. Essa mudança de percepção representa a relação com o saber desses professores na dimensão epistêmica porque passaram a perceber a importância da formação continuada para agregar conhecimento à sua prática educativa. 
Enfim, o professor de Matemática, quando sabe da incompletude da licenciatura para a sua formação e mobiliza-se, assim como tem motivações externas para buscar a formação continuada fora da escola denota um sentido para a formação continuada a partir da dimensão epistêmica, mas, também, identitária e social da relação com o saber. Eles vislumbram crescimento profissional e ascensão no mercado de trabalho.

A pesquisa está em fase de conclusão, mas os dados revelam novas possibilidades de continuar pesquisando, além do que as políticas públicas já anunciam como mudanças nas práticas educativas no Ensino Médio, por conseguinte, na ação do professor de Matemática.

\section{REFERÊNCIAS}

ALMEIDA, L. R. R. de. A relação com o saber e o ofício docente de professores da educação de jovens e adulto sem Assú, Rio Grande do Norte. IN: EJA EM DEBATE, vol. 1, n. 1. nov./2012. Florianópolis, 2012. Disponível em: http://incubadora.periodicos.ifsc.edu.br/index.php/EJA. Acesso em 13/Jun./2015.

ANTUNES, F. C. A. A relação com o saber e o estágio supervisionado em Matemática. Dissertação de Mestrado em Ciências e Educação Matemática. Universidade Estadual de Londrina - UEL. Londrina: UEL, 2007.

BRASIL. Ministério da Educação. Portaria MEC No 438, de 28 de maio de 1998. Institui o Exame Nacional do Ensino Médio - ENEM. Brasília: MEC, 1998.

CAMPOS, C. M. Saberes docentes e autonomia dos professores. Petrópolis: Vozes, 2013. CHARLOT, B. Da relação como o saber: elementos para uma teoria. Porto Alegre: Artmed, 2000.

CHARLOT, B. Relação com o saber, formação de professores e globalização: questões para educação de hoje. Porto Alegre: Artmed, 2005.

FREIRE, P. Pedagogia da autonomia: saberes necessários à prática educativa. São Paulo: Paz e Terra, 1996.

FREITAS, L. C. de A.; SAMPAIO, M. L. P. Discurso pedagógico: tecendo interação e conhecimentos.UERN. Disponível em: http://www.educadores.diaadia.pr.gov.br/arquivos /artigos_teses/2010/Lingua_Portuguesa/artigo/Artigo_luzinete.pdf. Acesso em: 15/12/2016.

GATTI, B. A. Grupo focal na pesquisa em ciências sociais e humanas. Série Pesquisa em Educação, v. 10. Brasília: Liber Livro, 2005.

MOREIRA, P. C.; DAVID, M. M. M. S. D.A formação matemática do professor: licenciatura e prática docente escolar. Belo Horizonte: Autêntica, 2010. 
PIMENTA. S. G. Formação de professores: identidade e saberes da docência. In: PIMENTA, S. G. (Org.). Saberes pedagógicos e atividades docentes. São Paulo: Cortez, 2008.

RIBEIRO, V. C. A relação com o saber de crianças com acolhimento institucional. Dissertação de Mestrado em Psicologia. Universidade de São Paulo. São Paulo: USP, 2012.

SOATO, A. M. L. Estudo sobre a relação com o saber e os saberes docentes, baseado no livro relação com o saber, formação dos professores e globalização, de Bernard Charlot. IN: VI ENCONTRO NACIONAL DE PESQUISA EM EDUCAÇÃ̃O EM CIÊNCIAS. De 01 a 04 de setembro de 1999. São Paulo. Disponível em: <http://www.nutes.ufrj.br/abrapec/vienpec/orais0.html>. Acesso em 05/Jun./ 2016.

TARDIF, M. Saberes docentes e formação profissional. Petrópolis: Vozes, 2013. 